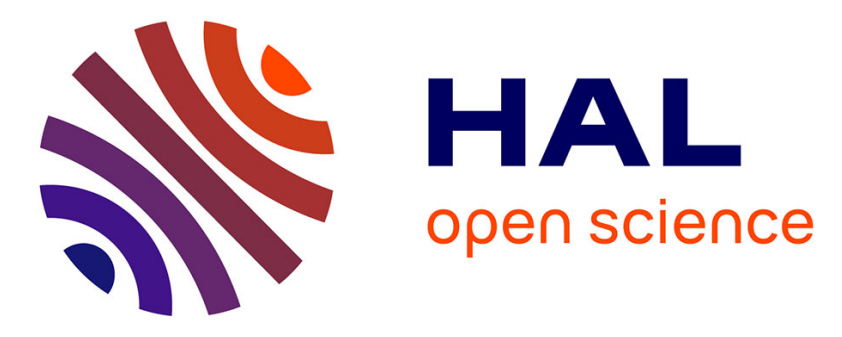

\title{
Impact of infarct location on functional outcome following endovascular therapy for stroke
}

Charlotte Rosso, Raphaël Blanc, Julien Ly, Yves Samson, Stéphane Lehericy, Benjamin Gory, Gautier Marnat, Mikael Mazighi, Arturo Consoli, Julien Labreuche, et al.

\section{To cite this version:}

Charlotte Rosso, Raphaël Blanc, Julien Ly, Yves Samson, Stéphane Lehericy, et al.. Impact of infarct location on functional outcome following endovascular therapy for stroke. Journal of Neurology, Neurosurgery and Psychiatry, 2018, 90 (3), pp.313-319. 10.1136/jnnp-2018-318869 . hal-01996268

\section{HAL Id: hal-01996268 \\ https: / hal.sorbonne-universite.fr/hal-01996268}

Submitted on 28 Jan 2019

HAL is a multi-disciplinary open access archive for the deposit and dissemination of scientific research documents, whether they are published or not. The documents may come from teaching and research institutions in France or abroad, or from public or private research centers.
L'archive ouverte pluridisciplinaire HAL, est destinée au dépôt et à la diffusion de documents scientifiques de niveau recherche, publiés ou non, émanant des établissements d'enseignement et de recherche français ou étrangers, des laboratoires publics ou privés. 
Title: Impact of infarct location on functional outcome following endovascular therapy for stroke

Authors: Charlotte Rosso (1,2), Raphael Blanc (3), Julien Ly (1,2), Yves Samson $(1,2)$, Stéphane Lehéricy (1,4), Benjamin Gory (5), Gautier Marnat (6), Mikael Mazighi (3), Arturo Consoli (7), Julien Labreuche (8), Suzana Saleme (9), Vincent Costalat (10), Serge Bracard (5), Hubert Desal (11), Michel Piotin (3), Bertrand Lapergue (7) for the ASTER Trial and Pitié-Salpêtrière Investigators.

\section{Authors affiliation}

1. Inserm U 1127, CNRS UMR 7225, Sorbonne Université, UPMC Univ Paris 06 UMR S 1127, Institut du Cerveau et de la Moelle épinière, ICM, F-75013, Paris, France

2. APHP-Urgences Cérébro-Vasculaires, Hôpital Pitié-Salpêtrière, Paris, France

3. Department of Diagnostic and Interventional Neuroradiology, Rothschild Foundation, Paris, France

4. APHP-Neuroradiology department, Hôpital Pitié-Salpêtrière, 75013 Paris, France

5. Department of Diagnostic and Interventional Neuroradiology, INSERM U947, University Hospital of Nancy, France

6. Department of Diagnostic and Interventional Neuroradiology, University Hospital of Bordeaux, Bordeaux, France

7. Department of Stroke Center and Diagnostic and Interventional Neuroradiology, University of Versailles and Saint Quentin en Yvelines, Foch Hospital, Suresnes, France

8. University Lille, CHU Lille, Department of Biostatistics, EA 2694-Santé Publique: Epidémiologie et Qualité des Soins, Lille, France

9. Department of Diagnostic and Interventional Neuroradiology, University Hospital of Limoges, Limoges, France 
10. Department of Diagnostic and Interventional Neuroradiology, Hôpital Gui de Chauliac, Montpellier, France

11. Department of Diagnostic and Interventional Neuroradiology, Guillaume et René Laennec University Hospital, Nantes, France

Corresponding author: Charlotte Rosso, 83 Boulevard de l'Hôpital 75013 Paris, France; Phone: +33142162103; Fax: +33142161839; E-mail: charlotte.rosso@gmail.com

Text Word Count 4148 words , 3 tables, 4 figures, 1 supplementary file, 32 references

Keywords: acute treatment, magnetic resonance imaging, prognosis 


\section{ABSTRACT}

Objectives: The relationship between stroke topography (i.e., the regions damaged by the infarct) and functional outcome can aid clinicians in their decision-making at the acute and later stages. However, the side (left or right) of the stroke may also influence the identification of clinically relevant regions. We sought to determine which brain regions are associated with good functional outcome at 3 months in left- and right-sided stroke patients treated by endovascular treatment using the Diffusion Weighted Imaging-Alberta Stroke Program Early Computed Tomography Score (DWI-ASPECTS).

Methods: Ischemic stroke patients $(\mathrm{n}=405)$ were included from the ASTER trial and PitiéSalpêtrière registry. Blinded readers rated ASPECTS on day one DWI. Stepwise logistic regression analyses were performed to identify the regions related to 3-month outcome in left $(\mathrm{n}=190)$ and right $(\mathrm{n}=215)$ sided strokes with the modified Rankin scale (mRS 0-2) as a binary independent variable and with the ten regions-of-interest of the DWI-ASPECTS as independent variables.

Results: Median NIHSS at baseline was 17 (IQR: 12-20), median age was 70 years (IQR: 5880) and median day-one NIHSS 9 (IQR: 4-18). Not all brain regions have the same weight in predicting good outcome at 3 months; moreover, these regions depend on the affected hemisphere. In left-sided strokes, the multivariate analysis revealed that preservation of the caudate nucleus, the internal capsule and the cortical M5 region were independent predictors of good outcome. In right-sided strokes, the cortical M3 and M6 regions were found to be clinically relevant.

Conclusion: Cortical non-motors areas related to outcome differed between left and rightsided strokes. This difference might reflect the specialization of the dominant and non- 
dominant hemispheres for language and attention, respectively. These results may influence decision-making at the acute and later stages.

Clinical Trial Registration-URL: http://www.clinicaltrials.gov. Unique identifier: NCT02523261. 


\section{INTRODUCTION}

The Alberta Stroke Program Early Computed Tomographic Score (ASPECTS) is a simple scoring system to estimate the extent of acute stroke lesions on diffusion-weighted imaging (DWI).[1, 2] The total score has been shown to help predict treatment response to thrombectomy as well as outcome.[3] The extent- or volume-based approach guides our decisions as clinicians. When there is a proximal occlusion of the middle cerebral artery (MCA), the more regions spared by the infarct there are, the more potential penumbral tissue has to be salvaged by recanalization. However, topography (i.e., location of infarcted tissue) rather than volume should be taken into account when considering functional outcome. $[4,5]$ Some areas are more eloquent and thus more clinically relevant to functional outcome than others due to their functional anatomy. The pathophysiological status of these specific areas (e.g., infarcted, penumbral, or normal) may be important for therapeutic decisions and prognosis.[4] For instance, if motor areas are inside the penumbral tissue but not yet infarcted, outcomes may be optimized by treating such patients, even if the NIHSS is low or the infarct volume small.

Another issue is that eloquent structures may differ depending on the side of the infarcted hemisphere.[5,6] Obviously, functional outcome assessed by the modified Rankin Scale (mRSs) depends not only on motor components but also captures disability for cognitive deficits such as aphasia for the left and neglect for the right hemisphere.[7] A group from Atlanta demonstrated, using DWI-ASPECTS, that only right parieto-occipital (M6) and left superior frontal (M4) involvement independently predicted poor outcome (defined as a modified Rankin Scale from 3 to 6).[6] To identify these regions, the template of the DWIASPECTS regions has proven useful, as it is increasingly used in clinical practice and shows 
good reliability.[8] Furthermore, the template is based on anatomical structures and thus the individual regions covering different parts of the deep and cortical territories.

The aim of this study was to determine which regions captured by DWI-ASPECTS at day one was related to 3-month good outcome and whether there was a difference in these critical regions according to the side of the stroke lesion.

To this purpose, we merged two large acute stroke datasets (ASTER trial[9] and PitiéSalpêtrière registry[10]) of patients treated by endovascular therapy (EVT) for a large vessel occlusion (LVO) in the anterior circulation and who had Magnetic Resonance Imaging (MRI) at day one, when the final extent of the infarct was reached. Our hypothesis was that critical regions associated with 3-month good outcome would differ between the left and righthemisphere, especially at the cortical level where the specificity of the dominant and nondominant hemispheres are more marked. 


\section{MATERIAL AND METHODS}

\section{Subjects}

The dataset included patients both from the ASTER trial and the Pitié-Salpêtrière registry treated by EVT for an anterior circulation ischemic stroke in the first 6 hours of stroke onset. The ASTER trial was a randomized controlled trial, which showed no statistical difference between aspiration or stent retriever as a frontline thrombectomy approach.[9] The PitiéSalpêtrière registry is a registry of patients treated with EVT, intravenous (IV) thrombolysis, or both[10]. For this study, we examined the same study period (2015-2017) as the ASTER trial. In both cohorts, patients underwent EVT within a 6-hour time window with or without IV thrombolysis (in a $4.5 \mathrm{~h}$ time window from symptom onset) if they had imaging evidence of an occlusion of the intracranial internal carotid artery or the origin (M1) or branches (M2) of the MCA (see supplementary methods for more information about the cohorts).

All patients were examined with the National Institute of Health Stroke Scale (NIHSS) at baseline and day one. The 3-month modified Rankin scale (mRS) was rated at follow-up. The modified Rankin scale is a commonly used scale for measuring the degree of disability or dependence in the daily activities of people who have suffered a stroke.[11]

To conduct this study, we included patients from both databases who had MRI performed one day after the stroke onset, when the final extent of the infarct was reached. In total, 319 patients from the ASTER trial and 86 patients from the Pitié-Salpêtrière registry were merged into a single dataset $(\mathrm{n}=405)$. The baseline characteristics of the 8 centers from the ASTER trial were compared to those of the Pitié-Salpêtrière registry. No difference between the baseline characteristics was detected (baseline (pretreatment) NIHSS, p: 0.18; day one 
NIHSS, p:0.56; baseline DWI-ASPECTS, p: 0.30; day one DWI-ASPECTS, p:0.05) except for age (p: 0.04). (Supplementary material, Table I)

ASTER was a randomized controlled trial led with ethics committee approval and written informed consent for each patient. In accordance with the French legislation, the PitiéSalpêtrière registry did not need approval by an ethics committee or written informed consent from patients, as it is a retrospective database implying only analysis of anonymized data collected prospectively as part of routine clinical care.

\section{DWI-ASPECTS scoring and frequencies of the affected DWI-ASPECTS regions}

DWI-ASPECT scores were rated on the MRI performed at day one after stroke onset by investigators blinded to the clinical data for each database. The total score as well as damage to each region-of-interest (ROI) was recorded. The ASPECTS template (Figure 1) is described at two levels: at the level of the basal ganglia for the following regions (M1 to M3, caudate-C, lenticular nucleus-L, internal capsule-IC, insula-I) and those superior to this level for M4 to M6 [1-3]. Three of these regions belong to the deep territory (C, IC and L) and seven to the cortical superficial territory (I, M1 to M6). One point is deducted for partial or total involvement by acute infarction in each of the 10 regions. A DWI-ASPECTS rating of 10 represents no visible infarction, and a score of 0 represents extensive infarction throughout the MCA territory.

As a first step, we determined the frequency of infarct damage in each region and whether certain regions were likely to be damaged together. As infarcts usually involve several regions at the same time and as the pattern of lesion topography depends on the territory vascularized by each artery, it seemed obvious that some regions would be more likely infarcted together and others less. We also computed correlation matrices between these 
regions to better identify which ones covaried with each other. Multiple comparisons were handled with Bonferroni corrections.

\section{Impact of hemisphere on the association between infarct topology and 3-month outcome}

First, all left and right DWI-ASPECTS ROIs were evaluated using univariate analyses in order to determine whether they were clinically relevant to good outcome at 3 months poststroke. Odds Ratios and 95\% Confidence Intervals (95\%CIs) were calculated. Then, we ran separate stepwise logistic regressions for left and right-sided strokes with the 3-month mRS binarized for a good outcome as the dependent variable. The independent variables were the DWI-ASPECTS ROIs found to be significant in the univariate analysis. A potential problem for this type of analysis is multicollinearity of the independent variables, which might affect the precision and choice of the variables. We therefore verified the absence/presence of multicollinearity with two factors. First, the variance inflation factor (VIF) was computed using JASP (Version 0.8.6, Amsterdam, The Netherlands). By convention, multicollinearity is considered present if the VIF of one variable was at least 10 [12]. Second, we also calculated the Condition Index (CIx) for the ten ROIs. The CI is a measure derived from Principal Component Analysis (PCA). A variable is considered collinear if the CIx was $>30$ [13].

\section{Statistical analysis}

Descriptive statistics are given as the median and IQR. Non-parametric tests were used for the comparison of continuous data. Comparisons of proportions were done with chi-square tests. Correlations between ROI damage were analyzed using the Spearman correlation coefficient. 95\% confidence intervals $(95 \% \mathrm{CI})$ are given with the correlations. Statistical analyses were performed with MedCalc (version 12.5.0, Belgium, 2013) for the univariate 
and stepwise logistic regression analyses and JASP, an open source R based program for the multicollinearity and principal component analyses. 


\section{RESULTS}

\section{Cohort}

Four hundred and five patients (median age: 70 years, IQR: 58-80, 55\% of males) with available DWI-ASPECTS at day one and 3-month mRS were included in the study. There were 190 left-sided strokes (47\%) and 215 right-sided stroke (53\%). Baseline clinical characteristics, as well as DWI-ASPECTS ROI involvement are summarized in table 1. NIHSS scores at baseline and at day one were statistically different between left and right stroke patients but not the 3-month mRS (whether considered as a dichotomized or continuous variable). The difference in the NIHSS could be expected as it measures the severity of strokes in the right and left hemisphere differently since 7 points are dedicated to aphasia and only 2 for neglect.[14, 15] 
Table 1. Demographics and radiological features of patients with left and right-sided stroke

\begin{tabular}{|c|c|c|c|}
\hline Median (IQR) & Left-sided stroke $n=190$ & $\begin{array}{c}\text { Right sided stroke } \\
n=215\end{array}$ & p-value \\
\hline Age (years) & $70(57-80)$ & $71(58-80)$ & 0.72 \\
\hline Gender (male, $\%$, n) & $59 \%(113)$ & $51 \%(109)$ & 0.13 \\
\hline Pre-treatment NIHSS* & $19(15-23)$ & $15(11-18)$ & 0.0001 \\
\hline NIHSS at day one* & $12(5-20)$ & $7(3-15)$ & 0.004 \\
\hline $\operatorname{rtPA}(\%, n)$ & $64 \%(122)$ & $64 \%(138)$ & 0.92 \\
\hline 3-month mRS & $12 \%(23)$ & $19 \%(41)$ & 0.07 \\
\hline 1 & $17 \%(32)$ & $24 \%(45)$ & 0.10 \\
\hline 2 & $16 \%(31)$ & $12 \%(23)$ & 0.30 \\
\hline 3 & $18 \%(34)$ & $14 \%(29)$ & 0.33 \\
\hline 4 & $13 \%(24)$ & $12 \%(26)$ & 0.87 \\
\hline 5 & $5 \%(9)$ & $8 \%(17)$ & 0.31 \\
\hline 6 & $19 \%(37)$ & $16 \%(34)$ & 0.50 \\
\hline 3-month mRS 0-2 \% (n) & $45 \%(86)$ & $50 \%(109)$ & 0.36 \\
\hline 3-month mRS 4-6 \% (n) & $37 \%(70)$ & $36 \%(77)$ & 0.91 \\
\hline DWI-ASPECTS at baseline & $7.5(5-9)$ & $7(5-9)$ & 0.23 \\
\hline DWI-ASPECTS at day one & $6(3-8)$ & $5.5(3-8)$ & 0.41 \\
\hline$\%(n)$ & $39 \%(74)$ & $46 \%(98)$ & 0.18 \\
\hline$\%(n)$ & $23 \%(43)$ & $30 \%(64)$ & 0.14 \\
\hline$\%(n)$ & $64 \%(121)$ & $75 \%(161)$ & 0.02 \\
\hline$\%(n)$ & $75 \%(142)$ & $70 \%(151)$ & 0.31 \\
\hline$\%(n)$ & $44 \%(83)$ & $44 \%(95)$ & 0.92 \\
\hline$\%(n)$ & $60 \%(114)$ & $65 \%(140)$ & 0.34 \\
\hline$\%(n)$ & $38 \%(72)$ & $37 \%(79)$ & 0.91 \\
\hline$\%(n)$ & $36 \%(69)$ & $26 \%(75)$ & 0.03 \\
\hline$\%(n)$ & $59 \%(113)$ & $60 \%(130)$ & 0.91 \\
\hline$\%(n)$ & $36 \%(68)$ & $32 \%(68)$ & 0.45 \\
\hline
\end{tabular}

$* \mathrm{P}<0.05$

Characterization of infarct topography according to the DWI-ASPECTS

Stroke lesions involved the cortical and deep territory simultaneously in 251 patients (62\%), were purely cortical in 110 patients (27\%), and purely deep in $44(11 \%)$. 
Table 2 indicates the frequency of multiple regions of damage for cortical and deep structures. A total of 355 patients ( $84 \%$ ) had at least one cortical ROI infarcted, with an equal distribution between each number of cortical ROIs involved (1 to 7). A total of 295 patients $(70 \%)$ had damage in at least one deep ROI and most of them in two $(43 \%, n=128)$.

The comparison between left- and right-sided infarcts revealed an asymmetry for the infarcted territories. The deep territory was less frequently involved in left $v s$. right-sided strokes (p: 0.02), driven by damage to the lenticular nucleus (Table 1, p: 0.02). The cortical M4 region was more frequently infarcted in left- than right-sided strokes (Table 1, p: 0.03).

The other comparisons did not show significant differences.

Table 2. Proportion of patients with damage for each ROI

\begin{tabular}{|c|c|c|c|c|c|c|c|c|}
\hline \multirow[b]{2}{*}{$\mathrm{N}=405$} & \multicolumn{2}{|c|}{$\begin{array}{l}\text { Entire cohort } \\
\qquad(n=405)\end{array}$} & \multicolumn{2}{|c|}{$\begin{array}{l}\text { Left-sided strokes } \\
\qquad(n=190)\end{array}$} & \multicolumn{2}{|c|}{$\begin{array}{l}\text { Right-sided strokes } \\
\qquad(\mathrm{n}=\mathbf{2 1 5})\end{array}$} & \multicolumn{2}{|c|}{ p-value* } \\
\hline & $\begin{array}{l}\text { Cortical } \\
\text { (7 ROIs) }\end{array}$ & $\begin{array}{c}\text { Deep } \\
\text { (3 ROIs) }\end{array}$ & $\begin{array}{l}\text { Cortical } \\
\text { (7 ROIs) }\end{array}$ & $\begin{array}{c}\text { Deep } \\
\text { (3 ROIs) }\end{array}$ & $\begin{array}{l}\text { Cortical } \\
\text { (7 ROIs) }\end{array}$ & $\begin{array}{c}\text { Deep } \\
\text { (3 ROIs) }\end{array}$ & Cortical & Deep \\
\hline $\begin{array}{ll}\text { None } & \% \\
\left(\mathbf{n} / \mathbf{n}_{\text {total }}\right) & \end{array}$ & $\begin{array}{c}12 \% \\
(50 / 405)\end{array}$ & $\begin{array}{c}27 \% \\
(110 / 405)\end{array}$ & $\begin{array}{c}10 \% \\
(19 / 190)\end{array}$ & $\begin{array}{c}33 \% \\
(63 / 190)\end{array}$ & $\begin{array}{c}14 \% \\
(31 / 215)\end{array}$ & $\begin{array}{c}22 \% \\
(47 / 215)\end{array}$ & 0.29 & 0.02 \\
\hline $\begin{array}{l}\text { At least } 1 \\
\%\left(n / n_{\text {total }}\right)\end{array}$ & $\begin{array}{c}84 \% \\
(355 / 405)\end{array}$ & $\begin{array}{c}73 \% \\
(295 / 405)\end{array}$ & $\begin{array}{c}90 \% \\
(171 / 190)\end{array}$ & $\begin{array}{c}67 \% \\
(127 / 190)\end{array}$ & $\begin{array}{c}86 \% \\
(184 / 2015)\end{array}$ & $\begin{array}{c}78 \% \\
(168 / 215)\end{array}$ & 0.28 & 0.02 \\
\hline $\begin{array}{l}1 \text { ROI infarcted } \\
\%\left(n / \mathbf{n}_{\text {total }}\right)\end{array}$ & $\begin{array}{c}19 \% \\
(67 / 355)\end{array}$ & $\begin{array}{c}34 \% \\
(98 / 295)\end{array}$ & $\begin{array}{c}22 \% \\
(37 / 171)\end{array}$ & $\begin{array}{c}33 \% \\
(42 / 127)\end{array}$ & $\begin{array}{c}16 \% \\
(30 / 184)\end{array}$ & $\begin{array}{c}33 \% \\
(56 / 168)\end{array}$ & 0.15 & 0.91 \\
\hline $\begin{array}{l}2 \text { ROIs infarcted } \\
\%\left(n / n_{\text {total }}\right)\end{array}$ & $\begin{array}{c}13 \% \\
(48 / 355)\end{array}$ & $\begin{array}{c}43 \% \\
(128 / 295)\end{array}$ & $\begin{array}{c}12 \% \\
(21 / 171)\end{array}$ & $\begin{array}{c}46 \% \\
(59 / 127)\end{array}$ & $\begin{array}{c}15 \% \\
(27 / 184)\end{array}$ & $\begin{array}{c}41 \% \\
(69 / 168)\end{array}$ & 0.46 & 0.36 \\
\hline $\begin{array}{l}3 \text { ROIs infarcted } \\
\%\left(n / n_{\text {total }}\right)\end{array}$ & $\begin{array}{c}11 \% \\
(38 / 355)\end{array}$ & $\begin{array}{c}23 \% \\
(69 / 295)\end{array}$ & $\begin{array}{c}11 \% \\
(20 / 171)\end{array}$ & $\begin{array}{c}21 \% \\
(26 / 127)\end{array}$ & $\begin{array}{c}10 \% \\
(18 / 184)\end{array}$ & $\begin{array}{c}26 \% \\
(43 / 168)\end{array}$ & 0.86 & 0.28 \\
\hline $\begin{array}{l}4 \text { ROIs infarcted } \\
\%\left(n / n_{\text {total }}\right)\end{array}$ & $\begin{array}{c}13 \% \\
(46 / 355)\end{array}$ & & $\begin{array}{c}12 \% \\
(21 / 171)\end{array}$ & & $\begin{array}{c}13 \% \\
(25 / 184)\end{array}$ & & 0.87 & \\
\hline $\begin{array}{l}5 \text { ROIs infarcted } \\
\%\left(n / n_{\text {total }}\right)\end{array}$ & $\begin{array}{c}15 \% \\
(55 / 355)\end{array}$ & & $\begin{array}{c}13 \% \\
(22 / 171)\end{array}$ & & $\begin{array}{c}18 \% \\
(33 / 184)\end{array}$ & & 0.21 & \\
\hline $\begin{array}{l}6 \text { ROIs infarcted } \\
\%\left(n / n_{\text {total }}\right)\end{array}$ & $\begin{array}{c}13 \% \\
(44 / 355)\end{array}$ & & $\begin{array}{c}13 \% \\
(22 / 171)\end{array}$ & & $\begin{array}{c}12 \% \\
(22 / 184)\end{array}$ & & 0.87 & \\
\hline $\begin{array}{l}7 \text { ROIs infarcted } \\
\%\left(n / n_{\text {total }}\right)\end{array}$ & $\begin{array}{c}16 \% \\
(57 / 355)\end{array}$ & & $\begin{array}{c}16 \% \\
(28 / 171)\end{array}$ & & $\begin{array}{c}16 \% \\
(29 / 184)\end{array}$ & & 0.89 & \\
\hline
\end{tabular}

\footnotetext{
*p-values refer to the comparison between left and right hemispheres.
} 
In order to determine which regions were more frequently affected, we computed the proportion of patients for whom a given ROI was infarcted alone or combined with others (Figure 2). The insula was the most frequent ROI damaged (72\%), followed by M2 (63\%), which corresponds to the same blood supply. For the deep ROIs, the lenticular nucleus was more often infarcted $(69 \%)$ than the other deep regions $(p<0.0001)$. Individual regions were rarely infarcted in isolation but in combination with other regions (figure 1). To identify which regions were more likely damaged together, we calculated the correlation matrix presented in Figure 3. We also plotted in pie charts the distribution of combination of regions (only two by two as the possibilities are too numerous) for each region (see supplementary figure I). As an example, M1 damage $(\mathrm{n}=178)$ was correlated to damage in all others ROIs of the deep and cortical territory. This is consistent with the fact that M1 was never infarcted alone (i.e., in isolation), but always with other ROIs such as the insula ( $95 \%$ of damage in M1 occurred simultaneously in the insula) and M2 (90\% of the damage co-occurred in the M1 and $\mathrm{M} 2$ regions). 


\section{Identification of regions related to 3-month outcome in left and right-sided strokes}

As a first step, we performed univariate logistic regression analyses to determine the weight of each ROI separately for 3-month good outcome (Table 3). For left-sided strokes, all DWIASPECTS regions were significant, with the internal capsule having the highest Odds-Ratio (OR) for explaining good outcome. For right-sided strokes, the caudate and lenticular nuclei were not significant, and the highest OR to explain good outcome was attributed to the right M6.

Table 3. Univariate logistic regression: Odds ratio (OR) of each ROI and its $95 \% \mathrm{CI}$ for 3-month good outcome in left and right-sided strokes. NS=not significant

\begin{tabular}{|l|c|c|c|c|c|c|}
\hline & \multicolumn{3}{|c|}{ Left-sided strokes (n=190) } & \multicolumn{2}{c|}{ Right-sided strokes (n=215) } \\
\hline & OR & $\mathbf{9 5} \%$ CI & p & OR & 95 \%CI & p \\
\hline C & 2.47 & $1.36-4.49$ & 0.002 & NS & & \\
\hline IC & 6.12 & $2.57-14.6$ & $<0.0001$ & 1.84 & $1.02-3.32$ & 0.04 \\
\hline L & 2.50 & $1.41-4.46$ & 0.001 & NS & & \\
\hline I & 2.53 & $1.36-4.70$ & 0.002 & 3.13 & $1.71-5.74$ & 0.0001 \\
\hline M1 & 3.13 & $1.73-5.67$ & 0.0001 & 3.21 & $1.84-5.61$ & $<0.0001$ \\
\hline M2 & 2.21 & $1.26-3.90$ & 0.005 & 3.52 & $1.96-6.32$ & $<0.0001$ \\
\hline M3 & 2.77 & $1.50-5.09$ & 0.0007 & 4.99 & $2.72-9.16$ & $<0.0001$ \\
\hline M4 & 3.02 & $1.62-5.60$ & 0.0005 & 2.97 & $1.65-5.33$ & 0.0002 \\
\hline M5 & 3.54 & $1.92-6.34$ & 0.0001 & 2.36 & $1.36-4.10$ & 0.0002 \\
\hline M6 & 3.22 & $1.71-6.04$ & 0.0003 & 5.14 & $2.71-9.75$ & $<0.0001$ \\
\hline
\end{tabular}

As none of the regions were detected as collinear (see supplementary material, "multicollinearity analysis", and supplementary figure II), we entered all of the 10 DWIASPECTS regions for the left-sided strokes. For left-sided strokes, the stepwise logistic regression $(\mathrm{p}<0.0001)$ retained the caudate nucleus $(\mathrm{C})(\mathrm{OR}: 2.07,95 \%$ CI: 1.06-4.06), the 
internal capsule (IC) (OR: 4.55, 95\% CI: 1.82-11.34), and M5 (OR: 3.39, 95\%CI: 1.77-6.48). The model yielded $66 \%$ of patients properly classified. As for right-sided strokes, we did not include the caudate and the lenticular nuclei as these regions were not significant in the univariate analysis. The model for right-sided strokes retained M3 (OR: 2.89, 95\%CI: 1.395.98) and M6 (OR: 2.76, 95\%CI: 1.28-5.98). The model yielded 67\% of patients properly classified. Adding rtPA administration as an independent variable did not change the results or the accuracy of the models. For left-sided strokes, the logistic regression retained the same ROIs in addition to rtPA administration (OR: 2.21, 95\% CI: $1.11-4.40$, p:0.02) with $67 \%$ of patients properly classified. For right-sided strokes, the model remained unchanged. 


\section{DISCUSSION}

In this study, we showed that not all DWI-ASPECTS regions have the same weight in predicting 3-month good outcome after EVT. Moreover, these regions differed with regard to the side of the infarct. The left caudate, internal capsule, and M5 region, when spared, were independently associated with good outcome. The right M3 and M6 were independently associated with good outcome. The other DWI-ASPECTS regions were not retained, implying that they were not independently predictive of good functional outcome

\section{Identification of clinically relevant regions for functional outcome in left and right-sided strokes}

In left-sided strokes, three independent regions were associated with good outcome when spared: two regions in the deep MCA territory, the caudate nucleus and the internal capsule, and one cortical region, the M5 frontoparietal region. Proximity of the deep MCA regions and their blood supplies anatomy explained why both regions were often damaged together (43\% in our cohort). The most frequent associations were either the caudate and lenticular nuclei or the lenticular nucleus and internal capsule together.[5, 6] For the caudate nucleus, its role in daily living activities and independency is somewhat surprising. Two explanations can be proposed. The first concerns its structural connectivity and its functional role. The caudate is an associative structure, which has been involved in motor, behavior, and dysexecutive disorders due to its important connections not only with the frontal but also the parietal lobes.[16, 17, 18] Second, the caudate's association with outcome could also be the reflection of an efficient deep artery collaterality. If the caudate nucleus is spared by an efficient collaterality network, this collaterality may also decrease the depth and extent of ischemia and therefore be a factor of good outcome in and of itself. On the contrary, the association between damage of the internal capsule and functional outcome was expected. 
Previous studies have found that corticospinal tract regions (corona radiata, posterior limb of the internal capsule) are crucial for motor outcome $[19,20]$ and consequently for daily living activities (and thus, the modified Rankin scale). Preservation of the left M5 was also associated with good outcome. The left M5 is a fronto-parietal region that contains important tracts for language (such as the arcuate fasciculus, which travels nearby) or for higher cognitive functions (such as the frontoparietal modules connected by $U$ fibers or some segments of the superior longitudinal fasciculus) (Figure 4).[21-23] Injury to this cortical region and the underlying white matter may therefore reduce possibilities of language recovery and contribute to more severe disability. In contrast to our results, Rangaraju et al. (2015) found that left M4 and not M5 was predictive of poor outcome when infarcted. Some differences between the two studies may explain this discrepancy, including the selection criteria, the distribution of infarction, the endpoint (poor outcome), the timing of the MRI scan that was performed in a wide range of hours (12-72h) as in [6], but more probably, the imprecision in the localization of lesions between raters for M4 and the adjacent M5.[6] It could be surprising that the left M1 or M3 is not retained in the logistic regression model as they are also important areas for language processing. We strongly believe that our findings and those of Rangaraju's are related to the underlying damage of the language dorsal white matter pathway.[6]

In right-sided strokes, good outcome was observed when right M3 and M6 (both are located in the right temporoparietal junction-TPJ) were spared from infarction. These results are in line with a Voxel Lesion Symptom Mapping (VLSM) study which reported asymmetrical patterns between hemispheres especially involving the right inferior parietal lobe and superior temporal gyrus.[5] Indeed, damage to the right TPJ in the non-dominant hemispheres may result in neglect [24], which in turn disturbs certain activities of daily living measured by 
the mRS. The ventral pathway including the inferior fronto-occipital fasciculus (IFOF) is located just beneath M3 as a direct connection from the occipital cortex to the prefrontal lobe [25], as well as the inferior longitudinal fasciculus (ILF) which connects the occipital cortex to the temporal lobe and runs laterally to the IFOF at the level of the temporo-occipital junction (Figure 4).[26] The role of these fasciculi in the right hemisphere is still controversial but has been shown to be involved in non-verbal semantic processes or nonverbal consolidation learning.[26] To summarize, the right TPJ and its structural connectivity are crucial for attention [27] - as pointed out by a recent meta-analysis - spatial orientation, and exploration [28], and its injury can lead to greater disability. It could be surprising that the internal capsule was found predictive in the left but not the right hemisphere. These results were also found in another cohort of 490 patients imaged at 48 hours post-stroke.[29] There was an association between injury to left motor areas and poor outcome that was not found in the right hemisphere. This could be because the major determinant of good outcome is the absence of neglect and that large strokes often injure areas responsible for motor function and neglect in a combined way. Indeed, other ROIs were not retained in the model, suggesting that they were either not associated with outcome at all or had no independent contribution to outcome, once other regions were accounted for. For example, a right basal ganglia infarct does not lower 3-month outcome.

\section{Characterization of infarct topography according to the DWI-ASPECTS}

We described the frequencies of damage to the DWI-ASPECTS regions in a large cohort of patients $(n=405)$. The insula, the lenticular nucleus and M2 were the three most frequently damaged regions in our cohort. Although most affected, these regions were not the most important in explaining functional outcome at 3 months, in agreement with a previous study.[6] This discrepancy may be explained by two factors: (i) these regions were rarely 
infarcted in isolation, and (ii) the weight of these regions on the functional outcome was lower when other regions were taken into account.

We highlighted a strong relationship between the damage in some DWI-ASPECTS regions. Correlation coefficients above 0.5 (considered as strong correlations in [6]) were observed between regions supplied by the same artery such as the insula and M2 (the rolandic operculum nearby the insula), M1 and M4 (the same area as M1 but at the supraganglionic slice), and M3 and M6 (two close regions at two different slices). Fortunately, we did not identify multiple collinearity with two independent measures in our cohort, which allowed us to enter all the variables in the logistic regression. In our study as well as in Phan et al. in 2006 [30] and Rangaraju et al.[6], the DWI-ASPECTS ROIs were not collinear, yet collinearity was found in one publication in 2013.[31]

Third, we found an asymmetry in the frequency of injury between left- and right-sided strokes in the deep (lenticular nucleus) and the superficial territory (M2). However, neither of the two regions was identified as a clinically relevant area.

Our study has several limitations. First, DWI-ASPECTS presents limitations for precisely evaluating infarct volume as there is no clear cut-off defined to count a region as affected or not. Second, its binary nature ( 0 if damaged, 1 if spared) does not take into account the proportion of the ROI actually damaged by the infarct. For example, an isolated injury of the cortical ribbon will be scored the same as a territorial damage involving $100 \%$ of the ROI. Nevertheless, this is one of the most used score nowadays in clinical routine.

Second, these results originated from cohorts where clinical assessments were performed using simple measures such as NIHSS at the acute and mRS at a mid-term stage. We cannot exclude that other regions may play a role in modalities not explored by the modified Rankin 
scale. In addition, the analysis was carried out on ischemic strokes of the anterior circulation (with exclusion of the posterior circulation and the subsequent areas-brainstem, cerebellum and occipital lobes). Third, one could argue that the multisite recruitment could be a bias. However, we rather view this as an advantage since the cohort was not biased by monocentric practices. The results should therefore be more generalizable to other centres. Finally, a complementary analysis would be to study DWI reversal for the same regions (i.e., the reversal of the DWI abnormalities between pretreatment and follow-up MRIs), in order to identify whether the reversal in the left C, IC, and M5 or the right M3 and M6 and not in other regions is associated with a dramatic early improvement.[32] This association would definitely prove that these specific regions are involved in processes that hamper independency. However, even if the sample size of our cohort was large, DWI reversal occurred only in less than $3.1 \%$ for the deep territory, and $5.5 \%$ for the cortical superficial territory (see supplementary material, Table II). Unfortunately, these percentages lead to insufficient statistical power to analyze the influence of laterality on DWI reversal of our clinically relevant regions.

\section{CONCLUSION}

Not all brain regions have the same weight in predicting good functional outcome at 3 months in ischemic stroke patients; moreover, these regions depend on the affected hemisphere. The left internal capsule and M5 as well as the right M3/M6 were independently associated, when spared, with 3-month good outcome. These results may affect decisionmaking in acute and later stages. Moreover, this study highlights the important role of these regions, especially the cortical regions, in brain function and processes leading to disability. 


\section{Acknowledgments}

The Pitié-Salpêtrière registry was supported by the French Ministry of Health grant EVALUSINV PHRC AOM 03 008. The research leading to these results has received funding from "Investissements d'avenir" ANR-10-IAIHU-06. We thank Eric Moulton for proofreading the English of our manuscript.

Competing Interests: The authors have no disclosures.

\section{Funding}

The ASTER trial was sponsored by the Fondation Ophtalmologique Adolphe de Rothschild. An unrestricted research grant was provided for the ASTER trial by Penumbra, Alameda, California. No grant was provided for this analysis and this study.

\section{Authors contribution}

CR: study design data analysis drafting of manuscript

BL and MP: study design, data collection, manuscript revision

RB, JL, YS, SL, BG, GM, MM, AC, SS, VC, SB and HD: data collection, manuscript revision

JL: data analysis, manuscript revision

\section{Patient consent and ethics}

ASTER was a randomized controlled trial led with ethic comittee approval and written inform consent for each patient. In accordance with French legislation, the Pitié-Salpêtrière registry did not need approval by an ethics committee or written informed consent from patients, as it is a retrospective database implying only analysis of anonymized data collected prospectively as part of routine clinical care. 


\section{REFERENCES}

1. Barber PA, Demchuk AM, Zhang J, et al. Validity and reliability of a quantitative computed tomography score in predicting outcome of hyperacute stroke before thrombolytic therapy. Aspects Study Group. Lancet 2000;355:1670-74.

2. Pexman JHW, Barber PA, Hill MD, et al. Use of the Alberta Stroke Program Early CT Score (ASPECTS) for assessing CT scans in patients with acute stroke. AJNR Am J Neuroradiol 2001;22:1534-42.

3. Desilles JP, Consoli A, Redjem H, et al. Successful reperfusion with mechanical thrombectomy is associated with reduced disability and mortality in patients with pretreatment DWI-ASPECTS $\leq 6$. Stroke 2017;48:963-69.

4. Rosso C, Samson Y. The ischemic penumbra: The location rather than the volume of recovery determines outcome. Curr Opin Neurol 2014;27:35-41.

5. Cheng B, Forkert ND, Zavaglia $\mathrm{M}$, et al. Influence of stroke infarct location on functional outcome measured by the modified Rankin scale. Stroke 2014;45:1695-1702.

6. Rangaraju S, Streib C, Aghaebrahim A, et al. Relationship between lesion topology and clinical outcome in anterior circulation large vessel occlusions. Stroke 2015;46:1787-92.

7. de Haan R, Limburg M, Bossuyt P, et al. The clinical meaning of Rankin 'handicap' grades after stroke. Stroke 1995;26:2027-30.

8. Fahed R, Lecler A, Sabben C, et al. DWI-ASPECTS (Diffusion-Weighted ImagingAlberta Stroke Program Early Computed Tomography Scores) and DWI-FLAIR (DiffusionWeighted Imaging-Fluid Attenuated Inversion Recovery) mismatch in thrombectomy candidates. Stroke 2018;49:223-27.

9. Lapergue B, Blanc R, Gory B, et al. Effect of endovascular contact aspiration vs. stent retriever on revascularization in patients with acute ischemic stroke and large vessel occlusion: The ASTER randomized clinical trial. JAMA Neurol 2017;318:443-52. 
10. Premat K, Bartolini B, Baronnet-Chauvet F, et al. Single-center experience using the 3MAX Reperfusion catheter for the treatment of acute ischemic stroke with distal arterial occlusions. Clin Neuroradiol. 2017. doi: 10.1007/s00062-017-0594-8.

11. Wilson LJT, Harendran A, Grant M, et al. Improving the assessment of outcomes in stroke: Use of a structured interview to assign grades on the Modified Rankin Scale. Stroke $2002 ; 33: 2243-46$.

12. Draper, N.R., Smith, H., 1998. Applied Regression Analysis. A Wiley-Interscience Publication, Danvers.

13. Kleinbaum, D.G., Kupper, L.L., Muller, K.E., Nizam, A. (Eds.), Applied Regression Analysis and Multivariate Methods. Brooks/Cole PublishingCompany, Pacific Grove.

14. Woo D, Broderick J, Kothari R, et al. Does the National Institutes of Health Stroke Scale favor left hemisphere strokes? Stroke 1999;30:2355-59.

15. Menezes NM, Ay H, Wang Zhu M, et al. The real estate factor: quantifying the impact of infarct location on stroke severity. Stroke 2007;38:194-97.

16. Ward P, Seri And S, Cavanna AE. Functional neuroanatomy and behavioural correlates of the basal ganglia: Evidence from lesion studies. Behav Neurol 2013;26:219-23.

17. Levy R, Dubois B. Apathy and the functional anatomy of the prefrontal cortex-basal ganglia circuits. Cereb Cortex 2006;16:916-28.

18. Whishaw IQ, O’Connor WT, Dunnett SB. The contribution of motor cortex, nigrostriatal dopamine and caudate-putamen to skilled forelimb use in the rat. Brain 1986;109:805-843.

19. Rosso C, Valabregue R, Attal Y, et al. Contribution of corticospinal tract and functional connectivity in hand motor impairment after stroke. PLoS One 2013;8, e 73164. 
20. Schulz R, Park $\mathrm{CH}$, Boudrias $\mathrm{MH}$, et al. Assessing the integrity of corticospinal pathways from primary and secondary cortical motor areas after stroke. Stroke 2012;43:2248-51.

21. Marchina S, Zhu LL, Norton A, et al. Impairment of speech production predicted by lesion load of the left arcuate fasciculus. Stroke 2011;42:2251-56.

22. Hickok G, Poeppel D. The cortical organization of speech processing. Nat Rev Neurosci 2007;8:393-402.

23. Rolheiser T, Stamatakis EA, Tyler LK. Dynamic processing in the human language system: synergy between the arcuate fascicle and extreme capsule. $J$ of Neurosci 2011;31:16949-57.

24. Thiebaut de Schotten M, Urbanski M, Duffau H, et al. Direct evidence for a parietalfrontal pathway subserving spatial awareness in humans. Science 2005 ; 309 : 2226-8.

25. Catani M, Thiebaut de Schotten M. A diffusion tensor imaging tractography atlas for virtual in vivo dissections. Cortex 2008; $44: 1105-32$

26. Lambon Ralph MA, Jefferies E, Patterson K, et al. The neural and computational bases of semantic cognition. Nat Rev Neurosci 2017;18:42-55.

27. Krall RC, Rottschy C, Oberwelland E, et al. The role of the right temporoparietal junction in attention and social interactionas revealed by ALE meta-analysis. Brain Struct Funct 2015;220:587-604.

28. Geng JJ, Vossel S. Re-evaluating the role of TPJ in attentional control: Contextual updating? Neurosci Biobehav Rev 2013;37:2608-20.

29. Wu O, Cloonan L, Mocking SJT, et al. Role of acute lesion topography in initial ischemic stroke severity and long-term functional outcomes. Stroke 2015;46:2438-44. 
30. Phan TG, Donnan GA, Koga M, et al. The ASPECTS template is weighted in favor of the striatocapsular region. NeuroImage 2006;31:477-81.

31. Phan TG, Demchuk A, Srikanth V, et al. Proof of concept study: Relating infarct location to stroke disability in the NINDS rt-PA trial. Cerebrovasc Dis 2013;35:560-65.

32. Tortora F, Cirillo M, Ferrara M, et al. DWI Reversibility after Intra-Arterial Thrombolysis. Neuroradiol J 2010;23:752-62. 


\section{FIGURE LEGENDS}

\section{Figure 1. Alberta Stroke Program Early CT Score (ASPECTS) Template.}

Panel A is the DWI slice at the level of the basal ganglia, and B at the supraganglionic level. C indicates caudate nucleus; I, insular ribbon; IC, internal capsule; L, lenticular nucleus; M1, anterior middle cerebral artery (MCA) cortex; M2, MCA cortex lateral to the insular ribbon; M3, posterior MCA cortex; and M4, M5, M6, anterior, lateral, and posterior MCA territory immediately superior to M1, M2, and M3. This patient has a total ASPECT score of 5. Image is presented in the neurological convention (left is left).

Figure 2. Distribution of damage in the cortical and deep territories of the DWIASPECTS ROIs. * $\mathrm{p}<0.005$. Blue represents the proportion of patients for whom the ROI is damaged with another and red for a ROI damaged in isolation.

Figure 3. Correlation matrix between damage to DWI-ASPECTS ROIs in the entire cohort

Correlation coefficients are given with the $95 \%$ CI. Color code is based on the strength of the correlations. ${ }^{* *} \mathrm{p}<0.0001,{ }^{*} \mathrm{p}<0.001, \S$ for $\mathrm{p}>0.005$ (does not survive multiple comparisons), NS=not significant.

Figure 4. Anatomical relationships between the M3 and M5 regions with white matter fasciculi on axial (A, C) and coronal slices (B, D) on DWI.

Top Row: The M5 region (red) overlapping with the arcuate fasciculus in yellow.

Bottom Row: The M3 region (red) overlapping with the IFOF (blue) and ILF (green). 


\section{ON LINE SUPPLEMENT}

\section{SUPPLEMENTARY METHODS}

\section{Subjects}

The ASTER trial was a muticentric $(n=8)$ randomized, controlled trial, which showed no statistical difference between aspiration or stent retriever as a frontline thrombectomy approach in patients treated by endovascular treatment in the first 6 hours,.

The Pitié-Salpêtrière registry is a registry of patients treated by EndoVascular Treatment, or IV thrombolysis, or both. For this study, we examined the same study period (2015-2017) as the ASTER trial, (i.e., once the pivotal EVT trials showed a benefit of performing EVT in anterior large vessel occlusion). We selected patients who underwent EVT with or without IV thrombolysis if they had imaging evidence of an occlusion of the intracranial internal carotid artery or the origin (M1) or branches (M2) of the middle cerebral artery to have the same inclusion criteria as the ASTER trial. Key exclusion criteria included cerebral infarction of the posterior circulation and prestroke modified Rankin Scale (mRS) score greater than 2 as well as the general contraindications for thrombolysis and thrombectomy.

To conduct this study, we excluded 19 patients from the ASTER trial with day one DWIASPECTS of 10. In total, 319 patients from the ASTER trial and 86 patients from the PitiéSalpetrière were merged into a single dataset. Investigators blinded to the clinical data for each database rated a posteriori each DWI-ASPECTS region and computed the total score. Indeed, in both cohorts, DWI-ASPECTS was not used as an inclusion or exclusion criteria to treat the patients.

Supplementary Table I. Characteristics of the 8 centers from the ASTER trial and the PitiéSalpêtrière (PS) registry

\begin{tabular}{|l|c|c|c|c|c|c|}
\hline $\begin{array}{l}\text { Median } \\
\text { (IQR) }\end{array}$ & $\mathrm{N}$ & $\begin{array}{c}\text { Age } \\
\text { (years })\end{array}$ & $\begin{array}{c}\text { Baseline } \\
\text { NIHSS }\end{array}$ & $\begin{array}{c}\text { Baseline } \\
\text { DWI- } \\
\text { ASPECTS }\end{array}$ & $\begin{array}{c}\text { Day one } \\
\text { NIHSS }\end{array}$ & $\begin{array}{c}\text { Day one } \\
\text { DWI- } \\
\text { ASPECTS }\end{array}$ \\
\hline Center 1 & 93 & $74(62-82)$ & $18(13-22)$ & $7(5-8)$ & $9(3-20)$ & $7(3-8)$ \\
\hline Center 2 & 61 & $68(57-79)$ & $15(8-20)$ & $7(5-8)$ & $8(5-18)$ & $5(3-7)$ \\
\hline
\end{tabular}




\begin{tabular}{|l|c|c|c|c|c|c|}
\hline Center 3 & 27 & $73(64-78)$ & $18(16-20)$ & $7(6-9)$ & $7(5-14)$ & $6(3-8)$ \\
\hline Center 4 & 26 & $73(65-80)$ & $16(10-19)$ & $7.5(7-9)$ & $8(3-14)$ & $4(2-6)$ \\
\hline Center 5 & 51 & $69(56-78)$ & $18(14-21)$ & $7(5-8)$ & $10(2-17)$ & $7(3-8)$ \\
\hline Center 6 & 16 & $68(62-83)$ & $17(13-18)$ & $7.5(5-10)$ & $15(8-18)$ & $5(4-8)$ \\
\hline Center 7 & 22 & $72(62-85)$ & $18(14-20)$ & $8(6-9)$ & $5(2-14)$ & $5.5(4-8)$ \\
\hline Center 8 & 6 & $70(60-79)$ & $17(8-20)$ & $8(5-9)$ & $5(0-14)$ & $6(3-9)$ \\
\hline PS registry & 80 & $62(51-78)$ & $18(11-20)$ & $7(4-8)$ & $12(5-18)$ & $4(2-7)$ \\
\hline
\end{tabular}

\section{SUPPLEMENTARY RESULTS}

\section{Multicollinearity analysis}

The Principal Component Analysis identified (Supplementary Figure I) that damage to deep regions covaried together and that of cortical regions covaried together as well.

\section{Supplementary Figure I. PCA analysis}

Variable plot created with principal component analysis (PCA) in the entire cohort. PCA is a tool capable of summarizing the most important linear relationships between variables and computing synthetic variables named components from the original variables. PCA provides a simple graph with visual and geometric representations of the correlation matrix. Here plotted is the damage to the 10 ROIs $\left(\mathrm{C}_{-} \mathrm{J} 1, \mathrm{IC} \_\mathrm{J} 1\right.$ and $\mathrm{L}_{-} \mathrm{J} 1$ for the deep territory, and M1_J1 to M6_J1 for the cortical territory) on a plane spanned by the first two components. The first component (horizontal axis) contains all the cortical ROIs and accounts for around $35 \%$ of the total variance of the dataset. The second component contains the deep ROIs and accounts for $15 \%$ of the variance. 
Variables factor map (PCA)

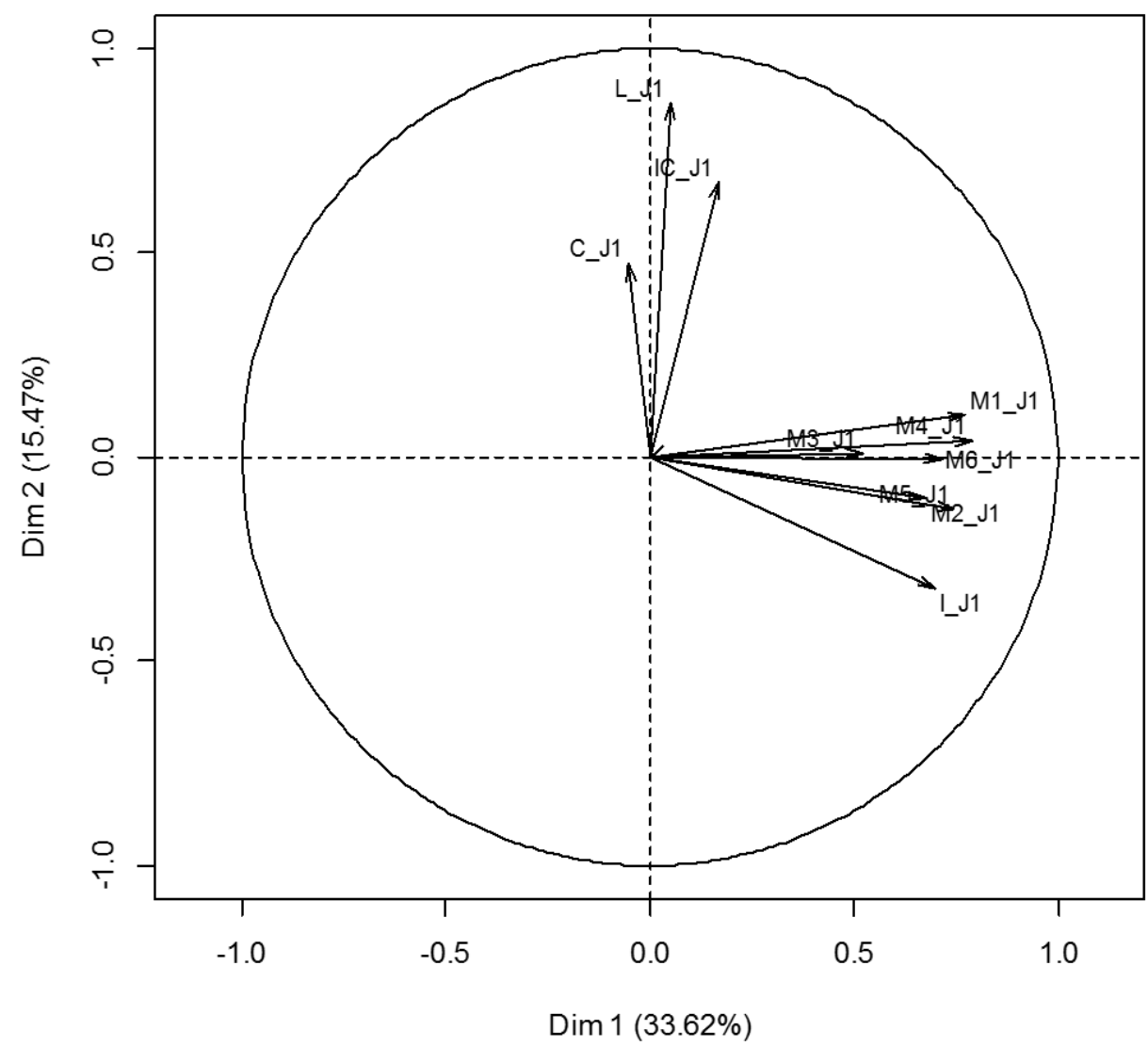

However, the variance inflation factor (VIF) factor and the Condition Index (CI) are reported for each DWI-ASPECTS region in Table I. None of the regions was found to be collinear. However, the total ASPECT score, which depends on the sum of the damaged ROIs was collinear and not entered in the logistic regression model.

\begin{tabular}{|l|c|c|c|c|c|c|c|c|c|c|c|}
\hline & C & IC & L & I & M1 & M2 & M3 & M4 & M5 & M6 & ASPECTS \\
\hline VIF & 1.290 & 1.299 & 1.441 & 1.506 & 1.959 & 1.808 & 1.642 & 1.833 & 1.574 & 1.762 & 147 \\
\hline CI & 2.615 & 3.774 & 4.197 & 4.684 & 5.332 & 5.416 & 5.613 & 6.688 & 7.681 & 8.147 & 80 \\
\hline
\end{tabular}

\section{Supplementary Figure II.}

Pie charts of the relative frequency of damage to each region of the deep territory with the others and each cortical region with one another. 


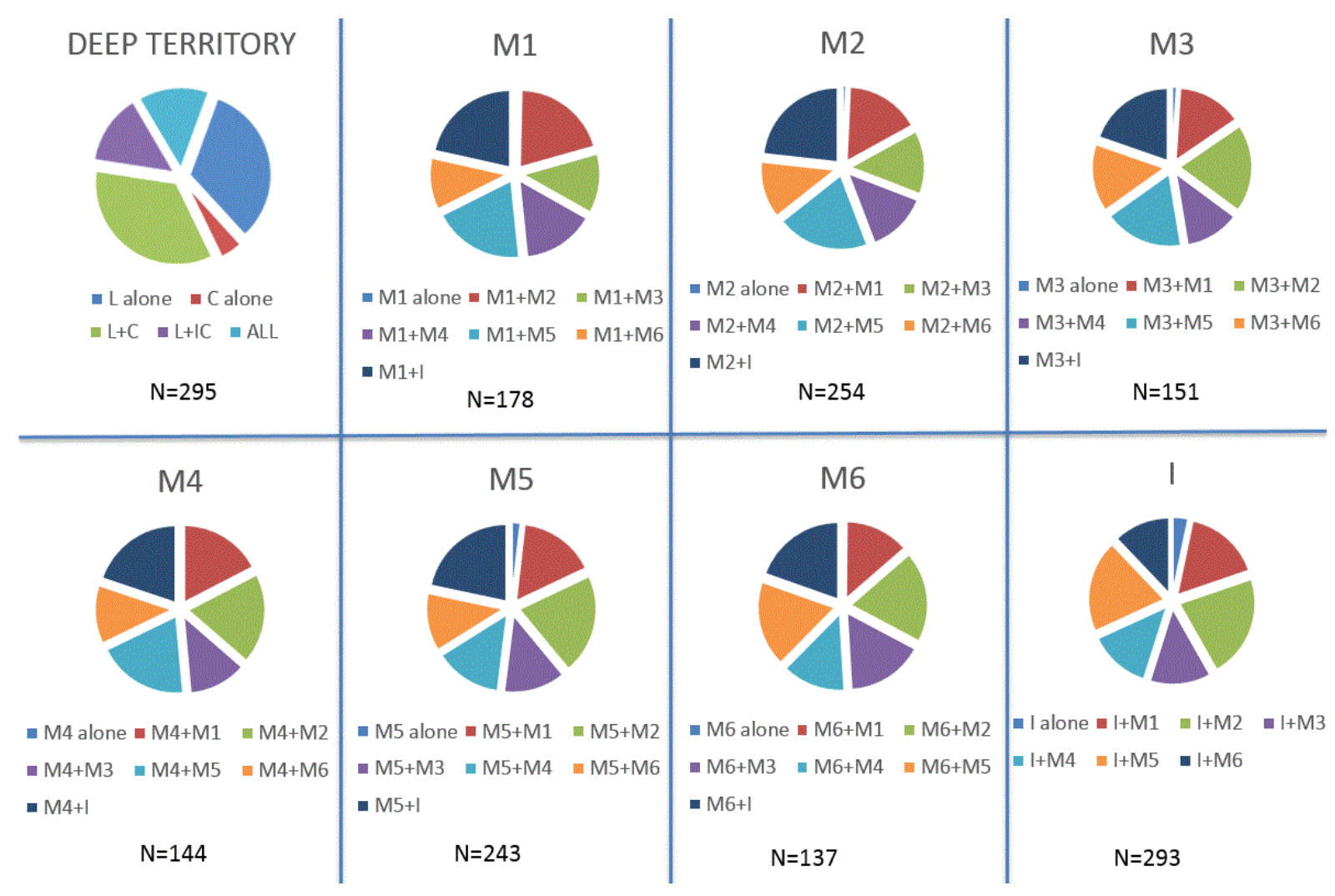

Supplementary Table II. Proportion of DWI reversal in the entire cohort and in left- and right- sided strokes.

The total number of patients was 382 (patients with pre-treatment and follow up MRI). The p-value refers to the comparison between the proportion of DWI reversal between right and left sided strokes.

\begin{tabular}{|l|c|c|c|c|}
\hline n (\%) & $\begin{array}{c}\text { Entire cohort } \\
\mathrm{N}=382\end{array}$ & $\begin{array}{c}\text { Left-sided } \\
\text { strokes } \\
\mathrm{N}=184\end{array}$ & $\begin{array}{c}\text { Right-sided } \\
\text { strokes } \\
\mathrm{N}=198\end{array}$ & -value \\
\hline C & $11(2.8 \%)$ & $6(3.2 \%)$ & $5(2.5 \%)$ & 0.91 \\
\hline IC & $10(2.6 \%)$ & $7(3.8 \%)$ & $3(1.5 \%)$ & 0.27 \\
\hline L & $12(3.1 \%)$ & $7(3.8 \%)$ & $5(2.5 \%)$ & 0.66 \\
\hline I & $16(4.2 \%)$ & $11(6.0 \%)$ & $5(2.5 \%)$ & 0.14 \\
\hline M1 & $11(2.8 \%)$ & $5(2.7 \%)$ & $6(3.0 \%)$ & 0.89 \\
\hline M2 & $13(3.4 \%)$ & $6(3.2 \%)$ & $7(3.5 \%)$ & 0.90 \\
\hline M3 & $13(3.4 \%)$ & $8(4.3 \%)$ & $5(2.5 \%)$ & 0.48 \\
\hline M4 & $11(2.8 \%)$ & $6(4.3 \%)$ & $5(2.5 \%)$ & 0.48 \\
\hline
\end{tabular}




\begin{tabular}{|l|c|c|c|c|}
\hline M5 & $21(5.5 \%)$ & $12(6.5 \%)$ & $9(4.5 \%)$ & 0.52 \\
\hline M6 & $17(4.5 \%)$ & $7(3.8 \%)$ & $10(5.0 \%)$ & 0.74 \\
\hline Total score & $52(13.6 \%)$ & $24(13.0 \%)$ & $28(14.1 \%)$ & 0.86 \\
\hline
\end{tabular}

